\title{
EDITORIAL
}

\section{The neurological effects of air pollution in children}

\author{
J. Sunyer*,\#,
}

nvironmental exposures in utero and during early life may permanently change the body's structure, physiology and metabolism, and lead to diseases in adult life [1]. Infants are particularly vulnerable because of their rapid growth and cell differentiation, immaturity of metabolic pathways and development of vital organ systems. The central nervous system has unprotected barriers and a broad time window of conformation, leading to a long period of vulnerability in the developmental process and to susceptibility to any environmental insult [2]. Research conducted among a limited series of pollutants (including lead, mercury and polycyclic aromatic hydrocarbons (PAH)) shows that early-life exposure to chemicals at current environmental levels can be neurotoxic years or even decades after exposure [3].

Traffic-related air pollution, basically urban outdoor pollution, is a global public health problem [4]. Cardiorespiratory effects and mechanisms have been fully investigated [5]. In contrast, little is known regarding neurological effects, with only some preliminary evidence. In rats, ultrafine carbon particles have been found in the olfactory bulb and the cerebrum and cerebellum after inhalation exposure [6]; this finding has been reproduced more recently with manganese particles directly translocated to the olfactory nerve from the nose to the brain [7]. In one study, dogs living in a highly polluted region in Mexico City (Mexico) had an increase in brain inflammation compared with animals living in a less polluted area [8]. The brain tissue of animals from Mexico City had higher levels of nuclear factor- $\kappa B$ activation and nitric oxide production, as well as the principal pro-inflammatory cytokines interleukin (IL)-1 and tumour necrosis factor (TNF)- $\alpha$, compared with the animals from the nonpolluted area [9]. In a study on human autopsies in Mexico City, exposure to severe air pollution has been associated with increased levels of cyclooxygenase (COX)-2 and accumulation of the 42-amino-acid form of $\beta$-amyloid, a cause of neuronal dysfunction [10].

There are two small studies in children from the general population exposed to urban air. The first study related PAH in particulate form, as collected with individual pumps during two

\footnotetext{
${ }^{*}$ Centre for Environmental Epidemiological Research (CREAL), ${ }^{*}$ Municipal Institute of Medical Research (IMIM), Universitat Pompeu Fabra, Barcelona, and "El Centro de Investigación Biomédica en Red de Epidemiología y Salud Pública (CIBERESP), Spain.

SUPPORT STATEMENT: J. Sunyer has received funds for research from the European Union, the government of Spain and Catalonia, and La Caixa Fundation.

STATEMENT OF INTEREST: None declared.

CORRESPONDENCE: J. Sunyer, CREAL-IMIM, Dr Aiguader 88, 08003 Barcelona, Spain. Fax: 34 933160575. E-mail: jsunyer@imim.es
}

consecutive days in 181 pregnant women from New York City (NY, USA), to mental health measured at age 3 yrs in their offspring [11]. The short measurement of the exposure (only 2 days), their narrow variability (only low and high levels), and the poor specificity of PAH (the principal source is smoking) resulted in preliminary research that is not very conclusive. The second study related average air pollution exposure during childhood (carbon particles at home address derived by spatial modelling) to intelligence at age 9 yrs in 202 children from Boston (MA, USA) [12]. The study, however, followed only $20 \%$ of those recruited and did not measure prospectively the variations in air pollution or the time-activity patterns of the participants. The two studies adjusted for potential confounders, such as socio-economic conditions or internal doses of lead, but failed to adjust for other factors, such as noise. Overall, these two studies were the first to translate into humans the evidence suggested in animal studies, but their deficiencies in size and design call for larger and more detailed research.

\section{THE LUNG AND THE UNDERLYING MECHANISMS}

Oxidative stress, changes in autonomous function and progression of atherosclerosis have been hypothesised to be mechanisms of the neurological effect of urban air pollution in humans at any age [13]. Among them, inflammation secondary to oxidative stress appears to be the major suspected culprit for delay in conformation and maturation during developmental steps. Even though most of the available research about the inflammatory effects of air pollution refers to the lungs, there is evidence that the oxidative stress and inflammation induced by particles translates systemically beyond the lungs [14]. For example, we found in an international longitudinal study of 1,003 adult subjects that particle count increased markers of systemic inflammation (IL-6 and fibrinogen peripheral levels) [15].

The major underlying hypothesis is that chronic respiratory tract inflammation may lead to brain inflammation by altering levels of circulating cytokines, such as TNF- $\alpha$ and IL- 1 . These cytokines have the ability to upregulate COX-2, a potent active mediator of inflammation, in capillary brain endothelium [16]. Changes in brain cytokine and chemokine expression in mice have been directly linked to intranasal exposure to ultrafine carbon [17]. Carbon particles themselves generally adsorb transition metals (including antimony, barium, copper, iron and zinc) emitted from traffic exhaust and also from tyres and brake wear. These metals, which are mainly generated by traffic in the current urban atmospheres [18], have been shown to induce oxidative stress in the lung [16].

An alternative hypothetical mechanism of the neurological effect of air pollution is based on the observation that ultrafine particles containing metals translocate directly to the brain, 
without entering the lung [7]. Changes in cognitive function in children have been shown to be associated with relatively low internal doses of lead [19] and mercury [3]. In addition to being linked to cognitive deficits in children, lead has been related to a diversity of behavioural problems (reading problems, school failure and delinquent behaviour), with a high social impact [20]. In experimental studies, some metals, such as mercury and lead, inhibit neuronal differentiation, myelinisation and synaptogenesis [21], but the specific mechanisms for leadinduced intellectual deficits have not been fully elucidated.

\section{THE CONSTELLATION OF FACTORS IN BRAIN MATURATION}

A well-known constellation of factors related to neurodevelopment could all play a confounding role or they could explain differences in vulnerability of the dose-response relationship between air pollution and neurodevelopment [20]. These factors must be considered and include, for example, the social environment (including parental psychological status), breastfeeding, diet, maternal smoking, birthweight and noise [22]; along with other pollutants such as lead, mercury, DDT and indoor air pollutants (those originating from indoor sources, such as heating and cooking, or from microbial contaminants, such as endotoxins). Endotoxins are the common structural component of Gram-negative bacteria in indoor air that induced chronic inflammation in the rat brain [23].

Therefore, it is important to examine diet, since it is a major source of antioxidants. Antioxidant defence mechanisms could be increased by dietary means (vitamins, omega-3 (docosahexaenoic acid) and omega-6 (arachidonic acid) fatty acids, and other micronutrients (zinc and folic acid)) to protect against air pollutants [24]. Antioxidants in the lung are the first line of defence against oxygen free radicals. All of these antioxidants are free radical scavengers and they react rapidly to limit interaction with lung fluid lipids and proteins [25]. The brain is particularly susceptible to free radical-mediated insult, due to its inherent biochemical and physiological characteristics, including high lipid content and energy requirements [26]. Reactive oxygen species are generated continuously in the nervous system during normal metabolism and neuronal activity [27]. Similarly, genetic background may result in a differential susceptibility toward the oxidative stress pathway [28]. For example, antioxidant supplementation with vitamins $C$ and $E$ appears to modulate the effect of ozone in asthmatic children homozygous for the GSTM1 null allele [29]. Inflammatory cytokines released in the periphery (e.g. respiratory epithelia) upregulate the innate immune Toll-like receptor 2 . Such activation and the subsequent events leading to neurodegeneration have recently been observed in lung lavage in mice exposed to ambient Los Angeles (CA, USA) particulate matter [30].

\section{CONCLUSION}

The study of chronic effects of urban air pollution should incorporate subtle health effects, such as functional delays in brain maturation and impairment of neurobehavioural competences, from early life exposures. The long-term consequences of these effects in the co-causation of neurodegenerative diseases have so far only been speculated, but it is time for multidisciplinary research in human populations (including neurobehavioural and lung examination, and assessments of individual exposure to air pollutants and antioxidants, and of the genetic contribution) to further investigate the suspicion that our urban air is neurotoxic for our children.

\section{REFERENCES}

1 Gluckman PD, Hanson MA. Living with the past: evolution, development, and patterns of disease. Science 2004; 305: 1733-1736.

2 Landrigan PJ, Sonawane B, Butler RN, Trasande L, Callan R, Droller D. Early environmental origins of neurodegenerative disease in later life. Environ Health Perspect 2005; 113: 1230-1233.

3 Grandjean P, Landrigan PJ. Developmental neurotoxicity of industrial chemicals. Lancet 2006; 368: 2167-2178.

4 World Bank. World Development Indicators. Environment: Air Pollution. Washington, World Bank Group, 2007. http: / / siteresources.worldbank.org/datastatistics/resources / table3_13.pdf

5 Kaiser J. Mounting evidence indicts fine-particle pollution. Science 2005; 307: 1858-1861.

6 Donaldson K, Tran L, Jimenez LA, et al. Combustionderived nanoparticles: a review of their toxicology following inhalation exposure. Part Fibre Toxicol 2005; 2: 10.

7 Elder A, Gelein R, Silva V, et al. Translocation of inhaled ultrafine manganese oxide particles to the central nervous system. Environ Health Perspect 2006; 114: 1172-1178.

8 Calderón-Garcidueñas L, Azzarelli B, Acuna H, et al. Air pollution and brain damage. Toxicol Pathol 2002; 30: 373-389.

9 Campbell A, Oldham M, Becaria A, et al. Particulate matter in polluted air may increase biomarkers of inflammation in mouse brain. Neurotoxicology 2005; 26: 133-140.

10 Calderón-Garcidueñas L, Reed W, Maronpot RR, et al. Brain inflammation and Alzheimer's-like pathology in individuals exposed to severe air pollution. Toxicol Pathol 2004; 32: 650-658.

11 Perera FP, Rauh V, Whyatt RM, et al. Effect of prenatal exposure to airborne polycyclic aromatic hydrocarbons on neurodevelopment in the first 3 years of life among innercity children. Environ Health Perspect 2006; 114: 1287-1292.

12 Suglia SF, Gryparis A, Wright RO, Schwartz J, Wright RJ. Association of black carbon with cognition among children in a prospective birth cohort study. Am J Epidemiol 2008; 167: 280-286.

13 Peters A, Veronesi B, Calderón-Garcidueñas L, et al. Translocation and potential neurological effects of fine and ultrafine particles: a critical update. Part Fibre Toxicol 2006; 3: 13.

14 Hirano S, Furuyama A, Koike E, Kobayashi T. Oxidativestress potency of organic extracts of diesel exhaust and urban fine particles in rat heart microvessel endothelial cells. Toxicology 2003; 187: 161-170.

15 Rückerl R, Greven S, Ljungman $P$, et al. Air pollution and inflammation (interleukin-6, C-reactive protein, fibrinogen) in myocardial infarction survivors. Environ Health Perspect 2007; 115: 1072-1080.

16 Campbell A. Inflammation, neurodegenerative diseases, and environmental exposures. Ann NY Acad Sci 2004; 1035: 117-132.

17 Tin-Tin-Win-Shwe, Yamamoto S, Ahmed S, Kakeyama M, Kobayashi T, Fujimaki H. Brain cytokine and chemokine 
mRNA expression in mice induced by intranasal instillation with ultrafine carbon black. Toxicol Lett 2006; 163: 153-160.

18 Steiner M, Boller M, Schulz T, Pronk W. Modelling heavy metal fluxes from traffic into the environment. J Environ Monit 2007; 9: 847-854.

19 Lanphear BP, Hornung R, Khoury J, et al. Low-level environmental lead exposure and children's intellectual function: an international pooled analysis. Environ Health Perspect 2005; 113: 894-899.

20 Bellinger DC. Very low lead exposures and children's neurodevelopment. Curr Opin Pediatr 2008; 20: 172-177.

21 Johansson C, Castoldi AF, Onishchenko N, Manzo L, Vahter M, Ceccatelli S. Neurobehavioural and molecular changes induced by methylmercury exposure during development. Neurotox Res 2007; 11: 241-260.

22 Clark C, Martin R, van Kempen E, et al. Exposure-effect relations between aircraft and road traffic noise exposure at school and reading comprehension: the RANCH project. Am J Epidemiol 2006; 163: 27-37.

23 Lehnardt S, Massillon L, Follett P, et al. Activation of innate immunity in the CNS triggers neurodegeneration through a Toll-like receptor 4-dependent pathway. Proc Natl Acad Sci USA 2003; 100: 8514-8519.
24 Kelly FJ. Dietary antioxidants and environmental stress. Proc Nutr Soc 2004; 63: 579-585.

25 Beck-Speier I, Dayal N, Karg E, et al. Oxidative stress and lipid mediators induced in alveolar macrophages by ultrafine particles. Free Radic Biol Med 2005; 38: 1080-1092.

26 Pajović SB, Saicić ZS, Spasić MB, Petrović VM. The effect of ovarian hormones on antioxidant enzyme activities in the brain of male rats. Physiol Res 2003; 52: 189-194.

27 Gurgueira SA, Lawrence J, Coull B, Murthy GG, GonzálezFlecha B. Rapid increases in the steady-state concentration of reactive oxygen species in the lungs and heart after particulate air pollution inhalation. Environ Health Perspect 2002; 110: 749-755.

28 Nebert DW, Vasiliou V. Analysis of the glutathione $S$-transferase (GST) gene family. Hum Genomics 2004; 1: 460-464.

29 Romieu I, Castro-Giner F, Kunzli N, Sunyer J. Air pollution, oxidative stress and dietary supplementation: a review. Eur Respir J 2008; 31: 179-197.

30 Mohankumar SM, Campbell A, Block M, Veronesi B. Particulate matter, oxidative stress and neurotoxicity. Neurotoxicology 2008; 29: 478-487. 